\title{
Alterations in Salivary IgA Levels in Infectious and Inflammatory Disorders of Upper Respiratory Tract
}

\author{
Seyed Abbas Hashemi ${ }^{1}$, Saeid Abediankenari ${ }^{2 *}$, Seyed Abdollah Madani ${ }^{3}$ \\ ${ }^{1}$ Faculty of Medicine, Student Research Committee, Mazandaran University of Medical Sciences, Sari, Iran. \\ ${ }^{2}$ Molecular and Cell Biology Research Center, Department of immunology, Faculty of Medicine, Mazandaran University of Medical Sciences, \\ Sari, Iran \\ ${ }^{3}$ Department of Ear,Nose,Throat, Head and Neck Surgery, Faculty of Medicine , Mazandaran University of Medical Sciences, Sari, Iran.
}

\section{Received: 14 Oct 2012}

Revised: 27 Dec 2012

Accepted: 18 Jan 2013

Corresponding Author:

Saeid Abediankenari

Mazandaran University of Medical

Sciences, Sari, Mazandaran, IRAN

Fax: +98-113543248

Email:abedianlab@yahoo.co.uk.

\begin{abstract}
:
Background: The airway surfaces are one of the most common ways of entry of infectious agents. The impact of upper respiratory tract diseases on salivary $\operatorname{IgA}$ production has not been fully understood. Therefore, in this study, we investigated the salivary IgA levels in patients suffered from upper respiratory tract diseases to indicate the effect of these diseases on salivary IgA production.

Materials and Methods: In this study, salivary IgA level of 156 patients with inflammatory diseases of the upper respiratory tract including chronic rhinosinusitis, ear and pharynx diseases have been evaluated by direct immunoenzymatic determination.

Results: In pharynx disorders $11.8 \%$ of patients were IgA deficient, $76.2 \%$ were normal and11.8 \% had elevated level of IgA .In patients with chronic rhinosinusitis IgA deficiency was observed in $9.2 \%, 75.9 \%$ were normal and there was an elevation in $14.8 \%$ of patients .In ear disorders $11.6 \%$ were $\operatorname{IgA}$ deficient , $76.7 \%$ normal and $11.6 \%$ had elevated IgA level.

Conclusion: This study provided evidence for the first time that changes in salivary $\operatorname{IgA}$ level are almost the same in different sites of infectious and inflammatory diseases of upper respiratory tract. Our investigation revealed that local up regulation of salivary $\operatorname{IgA}$ is not particular interest in majority of patients with upper respiratory tract infections.
\end{abstract}

Keywords: Salivary IgA; Upper respiratory tract diseases; Mucosal defense

Please cite this article as: Hashemi SA, Abediankenari S, Madani SA. Alterations in Salivary IgA Levels in Infectious and Inflammatory Disorders of Upper Respiratory Tract. Res Mol Med. 2013; 1 (1): 40-42

\section{Introduction}

Surfaces are the most common way of entry of infectious agents, allergens and carcinogens. These include the airways, the conjunctiva covering the eyes as well as gastrointestinal, urinary and genital tracts. Mucosal infections are the main cause of death for children below the age of 5 years old and kill 10 million children annually; unfortunately, there is no remedy for at least 6 million of this cases (1). Therefore, finding the defect of mucosal defense is the solution of these problems.

The mucosal immune system has improved the adaptive anti-inflammatory defense to set homeostasis by immune exclusion mediated by secretory IgA (SIgA) antibodies (Abs) to the clearance of pathogenic organisms from the mucosal surfaces by way of neutralizing toxins and viral particles, inhibiting adherence of pathogens, colonization and penetrationof mucosal surfaces by pathogenic microorganisms and immunosuppressive ways to limit overreaction against inoffensive luminal antigens. The secretary immunoglobulins are the most essential section of the antibody-dependent defense of the body (1-2).

Secretions of the mucosal layers are most commonly used for testing for the existence of SIgA Abs in order to examine local humoral immune responses. But the protective role of SIgA in upper respiratory tract infections is yet esoteric. Hence, the aim of this study is to evaluate the salivary IgA level as a 
secretary immunoglobulin in patients suffer from infectious and inflammatory disorders of upper respiratory tract including ear, pharynx and chronic rhinosinusitis (CRS) to find a noninvasive method to indicate the local humoral reaction mediated by SIgA in such patients.

\section{Methods and material}

\section{Patients and samples}

The study population included 156 patients with infectious and inflammatory disorders of ear, pharynx and CRS. Patients were recruited from the Ear, Nose, Throat, Head and Neck Surgery section of the university hospital (Mazandaran University of Medical Science, Sari, Iran).

In the opinion of investigators, participants with conditions that could affect salivary IgA level, such as malignancy, renal dysfunction, vascular disease, diabetes mellitus and malnutrition or any other conditions that could make the participants unsuitable for the study, were excluded.

All subjects gave their consent to participate in the study. This study was conducted in accordance with the declaration of Helsinki and good clinical practice according to International Conference on Harmonization guidelines.

\section{Immunoglobulin assay}

We collected fasting oral cavity secretions $(2 \mathrm{ml})$ of the patients and salivary $\operatorname{IgA}$ was determined by Neophlometric system. All assays were performed duplicate at the time of samples collection. According to literature data and on the results reported by the Dia. Metra kit, the normal range is $40-170 \mu \mathrm{g} / \mathrm{ml}$.

\section{Statistical analysis}

Quantitative data were presented as mean \pm SD (standard deviation). For statistical analysis, SPSS software (Version 15, Chicago, IL, USA) was used.

\section{Results}

The demographic data of the patients are summarized in Table 1. Patients divided to three groups (patients with infectious and inflammatory disorders of pharynx (a), ear (b) and CRS (c)).Each group had three subgroups including patients with low, normal and elevated level of salivary IgA. In group a , Mean \pm SD of patients with low level of IgA was $19.57 \pm 10.14$, for normal participants became $84.92 \pm 31.85$ and with elevated level $300.4 \pm 106.16$ .In group $b$, Mean \pm SD of patients with low level of IgA became $22.62 \pm 11.85$ for normal participants $84.14 \pm 27.69$ and in patients with elevated level of IgA was 313.6 \pm 117.36 . In group c, Mean \pm SD of patients with low level of $\operatorname{IgA}$ was $27.92 \pm 14.28$, for normal participants $86.03 \pm 41.91$ and in patients with elevated level $304 \pm 152.16$.

Table1. Demographic data of study population.

\begin{tabular}{|c|c|c|c|}
\hline \multicolumn{2}{|c|}{ Male (number \%) $\mathbf{F}$} & Female (number \%) & \multirow{2}{*}{$\begin{array}{c}\text { Age }(\text { mean } \pm \text { SD }) \\
38 \pm 23.31\end{array}$} \\
\hline Ear Disorders & $16(37.2 \%)$ & $27(62.7 \%)$ & \\
\hline Pharynx Disorders & $28(47.4 \%)$ & $31(52.5 \%)$ & $37.90 \pm 25.21$ \\
\hline Chronic Rhinosinusitis & $23(42.5 \%)$ & $31(57.4 \%)$ & $38.61 \pm 22.62$ \\
\hline
\end{tabular}

Elevated level of IgA was observed in 7 participants $(11.8 \%)$ in group a ,5 patients $(11.6 \%)$ in group b, and 8 subjects $(14.8 \%)$ suffered from CRS (c). low level of IgA was identified in 7 subjects $(11.8 \%)$ with pharynx disorders (arm a),5 patients (11.6\%) with ear disorders (group b), and 5 patients $(9.2 \%)$ with CRS (group c) (table2).

Table 2. Distribution of salivary IgA level in patients suffered from upper respiratory tract infections.

N elevated level of IgA normal level of IgA low level of IgA

$\begin{array}{lcccc}\text { Ear Disorders } & 43 & 5(11.6 \%) & 33(76.7 \%) & 5(11.6 \%) \\ \begin{array}{l}\text { Pharynx Disorders } \\ \text { Chronic }\end{array} & 7(11.8 \%) & 45(76.2 \%) & 7(11.8 \%) \\ \text { Rhinosinusitis } & 54 & 8(14.8 \%) & 41(75.9 \%) & 5(9.2 \%)\end{array}$

\section{Discussion}

Although it has been demonstrated that B-cell aggregation and immunoglobulin production are vital processes in the airway diseases but the mechanism of local humoral defense in upper respiratory tract mediated by salivary IgA has not been well defined. So, in this study, we evaluated salivary $\operatorname{IgA}$ level in infectious and inflammatory disorders of upper respiratory tract to elucidate local humoral reaction in inflamed mucosa.

Probably SIgA may work as antiseptic shell at the mucosal membrane by preventing bacterial adherence and influx of microorganisms. In situations associate with disruption of the mucosal barrier with manufacture of inflammatory mediators, SIgA provokes dendritic cells expressing Fc $\alpha$ RI which play a vital role either as a second line of defense against bacterial infection or by arming the immune system to confront with exogenous antigens (3). Fc $\alpha$ RI cannot be detected by immunohistochemistry on epithelial Langerhans cells (LC), indicating that LC might neglect $\operatorname{IgA}$ immune complexes within the epithelium in the lack of a destruction of the epithelial barrier (4).

Mucosal inductive sites consist of the Peyer's patches or gut-associated lymphoid tissues as well as the Waldeyer's ring of tonsils and adenoids as 
nasopharyngeal associated lymphoid tissues, which collectively comprise a mucosa-associated or MALT network for continuous supply of memory B and T cells to mucosal effectors sites $(5,7)$. Studies claimed that Peyer's patches play an important role in the induction of SIgA and oral tolerance (8-9).

One of the most commoncon genital immunodeficiency is $\operatorname{Ig} \mathrm{A}$ deficiency (10-11). $\operatorname{Ig} \mathrm{A}$ deficiency is thought to be a non-important condition needing only common pediatric care. Although onethird of IgA-deficient patients are symptomatic but most of them have no clinical signs (12). The presence of CRS in predominantly humoral immunodeficiencies, has been reported in few studies (13-14).

Herein, in the current study, we tried to find that salivary IgA elevation has considerable implication for the local activation of Abs in the upper airway infections or not. In various groups of our research population about $76.7 \%$ in infectious and inflammatory disorders of ear, $76.2 \%$ in pharynx, and $75.9 \%$ in CRS had normal level of salivary IgA which showed in most of our study population salivary IgA didn't indicate reportable change (table2). Our study claimed that in different parts of upper respiratory tract the local mucosal defense is almost the same.

There are few published researches which exactly examined the salivary $\operatorname{IgA}$ production in infectious and inflammatory disorders of upper respiratory tract but in this relation, Finocchi et al. examined humoral immune defects in 67 non-atopic patients with recurrent infections and they revealed $55 \%$ of the research populations were deficient (15). In consistent with our work, IgA deficiency as one of humoral immune defects was reported in $11.8 \%$ patients with inflammatory disorders of pharynx, 9.2 $\%$ in CRS and $11.6 \%$ in inflammatory disease of ear. May a et al. evaluated serum immunoglobulins of 254 patients with refractory CRS. Their team reported that 22 patients had common variable immunodeficiency (16). Likewise in our research, IgA deficiency was observed in 5 patients among 54 patients suffered from CRS.

\section{Conclusion}

In conclusion, our research revealed that local overproduction of salivary $\operatorname{IgA}$ is particular interest in $12.7 \%$ of patients with upper respiratory tract infections. Low IgA levels can be detected in a considerable proportion of patients with upper respiratory tract disorders.

\section{Acknowledgment}

This study was supported by a grant from Mazandaran University of medical sciences.

\section{References}

1. Brandtzaeg P. Mucosal Immunity: Induction, Dissemination, and effector Functions. Scand J Immuno. 2009; 70(6): 505-15. PMID: 19906191

2. Williams RC, Gibbons RJ. Inhibition of bacterial adherence by secretory immunoglobulin A: A mechanism of antigen disposal.Science.1972; 177(4050):697-9. PMID: 5054144

3. Geissmann F, Launay P, Pasquier B, Lepelletier Y, Leborgne M, Lehuen A, et al. A subset of human dendritic cells expresses $\operatorname{Ig} \mathrm{A}$ Fc receptor (CD89), which mediates internalization and activation upon cross-linking by IgA complexes. J Immunol. 2001; 166(1):346-52. PMID: 11123311

4. Reterink TJ, Levarht EW, Klar-Mohamad N, Van Es LA, Daha MR. Transforming growth factor-beta 1 (TGF-beta 1) downregulates IgA Fc- receptor (CD89) expression on human monocytes. Clin Exp Immunol. 1996; 103(1):161-6. PMID: 8565277

5. Bienenstock J, McDermott M, Befus D, O'Neill M .A common mucosal immunologic system involving the bronchus, breast and bowel. Adv Exp Med Biol 1978; 107:53-9. PMID: 742502

6. Mestecky J, McGhee JR. Immunoglobulin A (IgA): molecular and cellular interactions involved in IgA biosynthesis and immune response. Adv Immunol 1987; 40: 153-245. PMID: 3296685

7. Hashemi SA, Abediankenari S, Madani SA, Akbari M. Comparison of salivary $\operatorname{IgA}$, tear $\operatorname{IgA}$ and serum $\operatorname{IgE}$ in patients suffering from chronic rhinosinusitis. Int $\mathrm{j}$ med invest. 2012; 1(1):31-7.

8. Yamamoto M, Rennert P, McGhee JR, Kweon MN, Yamamoto $\mathrm{S}$, Dohi $\mathrm{T}$, et al. Alternate mucosal immune system: organized Peyer's patches are not required for $\operatorname{IgA}$ responses in the gastrointestinal tract. J Immunol. 2000; 164(10):5184-91. PMID: 10799877

9. Fujihashi K, Dohi T, Rennert PD, Yamamoto M, Koga T ,Kiyono H. Peyer's patches are required for oral tolerance to proteins. Proc Natl Acad Sci U S A. 2001; 98(6): 3310-5. PMID: 11248075

10. Schaer FM, Monteiro RC, Volanakis JE, Cooper MD. Selective IgA deficiency. Immunodefic Rev. 1991; 3(14):15-44. PMID: 1931006

11. Conley ME, Notarangelo LD, Etzioni A .Diagnostic criteria for primary immunudeficiencies. Clin Immunol.1999; 93(3): 190-7. PMID: 10600329

12. Carneiro-Sampaio MMS, Carbonare SB, Rozentraub RB, de Araujo MN, Riberiro MA, Portom H, et al .Frequency of selective IgA deficiency among Brazilian blood donors and healthy pregnant women. Allergol Immunopathol (Madr). 1989; 17(4): 213-6. PMID: 2816663

13. Ramesh S, Brodsky L, Afshani E, Pizzuto M, Ishman M, Helm $\mathrm{J}$, et al .Open trial of intravenous immune serum globulin for chronic sinusitis in children. Ann Allergy Asthma Immunol. 1997; 79(2): 119-24. PMID: 9291415

14. Sethi DS, Winkelstein JA, Lederman H, Loury MC. Immunologic defects in patients with chronic recurrent sinusitis: diagnosis and management. Otolaryngol Head Neck Surg. 1995; 112(2): 242-7. PMID: 7838546 
15. Finocchi A, Angelini F, Chini L, Di Cesare S, Cancrini C, Rossi P, et al. Evaluation of the humoral immunodeficiencies in a pediatric population affected by recurrent infections. Pediatr Allergy Immunol. 2002; 13(6): 443-7. PMID: PMID:12485321
16. May A, Zielen S, von Ilberg C, Weber A .Immunoglobulin deficiency and determination of pneumococcal antibody titers in patients with therapy-refractory recurrent rhinosinusitis. Eur Arch Otorhinolaryngol.1999; 256(9):445-9. PMID: 10552223 